\title{
PERFIL DOS INCÊNDIOS FLORESTAIS NO BRASIL DE 1994 A 1997
}

\author{
Ronaldo Viana Soares \\ Juliana Ferreira Santos ${ }^{2}$
}

\begin{abstract}
RESUMO
O conhecimento do perfil dos incêndios florestais é muito importante para o planejamento do controle dos mesmos. O objetivo deste trabalho foi estabelecer o perfil dos incêndios florestais no país através de dados coletados, em áreas protegidas, no período de 1994 a 1997, através de formulários preenchidos por empresas e instituições florestais. Foram registrados e informados 1.957 incêndios e apesar deste número não representar a totalidade dos incêndios ocorridos no período estudado, constituiu-se numa base confiável para se conhecer as principais características dos incêndios. Os resultados mostraram que a área média atingida por incêndio no período analisado foi de aproximadamente 135 ha, sendo Minas Gerais o estado líder, tanto em número de incêndios informados $(62,7 \%$ do total) como em área queimada $(25,2 \%)$. O grupo "Incendiários" foi a principal causa dos incêndios, com 56,6\% das ocorrências, vindo a seguir as "Queimas para limpeza" com 22,1\%. Com relação à área queimada o grupo "Queimas para limpeza", com 74,1\% da superfície atingida, foi a principal causa, ficando o grupo "Incendiários" em segundo lugar com 19,8\%. A principal estação de incêndios no país se estende de julho a novembro, quando ocorreram 79,2\% dos incêndios, correspondendo a 98,6\% da área atingida. O maior número de incêndios (39,7\% das ocorrências) foi registrado em "Outro tipo de vegetação", que inclui cerrado, capoeira e campo. Com relação à área atingida, entretanto, 92,5\% foi registrada em "Florestas Nativas". Quanto à distribuição dos incêndios através das classes de tamanho, 23,9\% foi enquadrado na classe I ( $<0,1$ ha). É importante ressaltar que quanto maior a eficiência no combate aos incêndios, maior é a concentração dos mesmos na classe I. Apesar de corresponder a apenas 2,4\% das ocorrências, os incêndios da classe V (>200,0 ha) foram responsáveis por $94,5 \%$ da área queimada.

Palavras chave: Incêndio florestal, Estatística de incêndios, Incêndios no Brasil, Proteção florestal, Fogo
\end{abstract}

\section{FOREST FIRE STATISTICS IN BRAZIL FROM 1994 TO 1997}

\section{ABSTRACT}

Forest fire statistics knowledge is an important tool for fire control planning. The objective of this research was to collect information on forest fire occurrence in Brazilian protected areas in the period of 1994 to 1997. The analyzed variables were the number of fires and burned areas per state of the federation, monthly distribution, probable causes, affected vegetation, size class distribution, and average burned area per fire. Results showed that the average burned area per fire was approximately 135 ha and Minas Gerais ranked first, both in number of registered fires $(62.7 \%)$ and burned surface $(25.2 \%)$. Incendiary, with $56.6 \%$ of the occurrences was the leading cause, followed by debris burning with $22.1 \%$. However, as for the affected area, Debris burning was the leading cause $(74.1 \%)$, followed by Incendiary $(19.8 \%)$. The fire season extends from July to November, when $79.2 \%$ of the fires occurred, corresponding to $98.6 \%$ of the burned surface. Miscellaneous, that includes savanna, secondary growth forest, and grassland were the most affected vegetation type (39.7\% of the occurrences). In relation to the burned surface, Native Forest (92.5\%) ranked first. The distribution of the registered fires through the size classes presented $23.9 \%$ of the occurrences in Class I $(<0.1 \mathrm{ha})$, whereas $94.5 \%$ of the burned area were result of Class V (> 200 ha) fires. Size Class II (0.1 to 4.0 ha), with $49.1 \%$ of the occurrences, ranked first in number of registered fires during the analyzed period.

Key-words: Forest fire, Fire statistics, Fire behavior, Brazilian fires, Forest protection

${ }^{1}$ Professor Titular do Curso de Engenharia Florestal da UFPR (rvsoares@ floresta.ufpr.br)

${ }^{2}$ Acadêmica do Curso de Engenharia Florestal da UFPR; Bolsista de Iniciação Científica.

Recebido para publicação: 26/06/2002

Aceito para publicação: 07/11/2002 


\section{INTRODUÇÃO}

Dentre os vários agentes que afetam os recursos florestais, o fogo parece ser a maior calamidade. Florestas e outros tipos de vegetação estão constantemente expostos à ocorrência de incêndios de diferentes intensidades. Em muitos países a situação tem se agravado devido ao aumento da população, ao acúmulo de material combustível e à incidência cada vez maior de causas humanas, principalmente incendiários.

O Brasil, desde a década passada, tem sido alvo periódico de críticas de organizações conservacionistas e mesmo instituições governamentais de outros países, com relação à falta de proteção de suas florestas contra o fogo. É comum se ouvir, ver e ler notícias informando da existência de milhares de focos de fogo no país, que na verdade podem ser incêndios ou, na maioria das vezes, queimadas, controladas ou não, principalmente durante a estação mais crítica, geralmente de julho a outubro. No entanto, quando se pergunta o número de incêndios e a superfície queimada anualmente no país ninguém é capaz de informar, pela simples razão de não haver estatísticas confiáveis sobre os mesmos.

Apesar da falta de informações precisas, sabe-se que o fogo é um problema sério para florestas nativas e plantadas em alguns ecossistemas brasileiros. Portanto, é necessário se tomar providências no sentido de reduzir o impacto do fogo sobre as florestas e outras formas de vegetação.

Para se estabelecer uma política adequada de prevenção de incêndios é necessário conhecer as estatísticas referentes aos mesmos, isto é, saber onde, quando, e porquê eles ocorrem. A falta dessas informações pode levar a um dos dois extremos: gasto muito alto, acima do potencial de danos ou gasto muito pequeno, colocando em risco a sobrevivência das florestas.

É fundamental saber onde ocorrem os incêndios para se definir as regiões de maior risco e estabelecer programas intensivos de prevenção para essas regiões. É necessário saber quando ocorrem para se estruturar os serviços de prevenção e combate dentro de limites economicamente viáveis, ativando o sistema durante os períodos críticos e desativando-o nos meses de menor risco. Finalmente, é preciso conhecer as principais causas dos incêndios para se fazer um trabalho objetivo de prevenção, visando a redução daquelas causas mais freqüientes.

É importante também conhecer outros aspectos dos incêndios, como o tipo de vegetação atingida, superfícies queimadas, tempo de ataque e recursos utilizados no combate. Essas informações são essenciais para se avaliar a eficiência do controle dos incêndios florestais, tanto em uma determinada região como no total do país.

Apesar da importância do assunto, não existem dados estatísticos atualizados que permitam conhecer o perfil dos incêndios florestais no Brasil. Apenas algumas empresas florestais têm mantido registro confiável das ocorrências ao longo dos anos (Soares 1992). Em termos de país, as únicas informações existentes referem-se aos anos de 1983 a 1987 e foram coletadas através de um projeto conjunto FUPEF/IBAMA (Soares $1984 ; 1988$ e 1989).

O objetivo principal deste trabalho foi recomeçar a coleta, análise e divulgação dos dados referentes à ocorrência de incêndios florestais no país a fim de se obter informações que possibilitem a avaliação dos setores de prevenção e combate e contribuam para a tomada de decisões que tornem mais eficientes os sistemas de proteção das florestas contra o fogo.

\section{METODOLOGIA}

A base de dados para o desenvolvimento da pesquisa foi o conteúdo dos questionários recebidos de empresas e outras instituições florestais, contendo as informações relativas aos incêndios florestais ocorridos no país. Os questionários, acompanhados de cartas explicando a finalidade e importância do projeto, haviam sido encaminhados a empresas florestais, associações de reflorestadores, diretores de parques e florestas nacionais, estaduais e municipais, superintendências do IBAMA, institutos (ou entidades equivalentes) estaduais de florestas e outras organizações afins, para cobrir o maior universo possível de entidades geradoras de informações.

As informações solicitadas nos questionários foram as seguintes: $a$ ) nome da empresa ou instituição onde ocorreu o incêndio; b) local e data; $c$ ) área queimada; $d$ ) tipo de 
vegetação atingida; $e$ ) hora de detecção do fogo; $f$ ) hora do início do combate; $g$ ) pessoal e equipamentos empregados no combate; $h$ ) hora em que o fogo foi controlado; $i$ ) causa provável do incêndio; $j$ ) observações complementares; $k$ ) identificação do responsável pelas informações.

Os questionários recebidos, contendo as informações solicitadas, foram separados por estado e devidamente arquivados. As informações neles contidas foram digitadas $\mathrm{e}$ armazenadas em meio magnético, formando o arquivo básico das estatísticas de incêndios florestais no país no período de 1994 a 1997.

Os dados extraídos dos questionários foram tabulados de diversas maneiras a fim de proporcionar a maior quantidade possível de informações sobre a ocorrência de incêndios no país e em cada estado. Além das estatísticas fundamentais de número de incêndios $\mathrm{e}$ respectivas áreas queimadas, foi feita a distribuição pelos meses do ano, a identificação da causa provável e a classificação segundo o tamanho da área queimada.

\section{Distribuição dos incêndios através dos Estados}

Os dados referentes ao número de incêndios e as respectivas áreas queimadas foram tabulados por estado para se observar as diferenças regionais. Os nomes das empresas e instituições onde ocorreram os incêndios foram omitidos para garantir-lhes o anonimato.

\section{Distribuição dos incêndios através dos meses do ano}

Tanto os dados de ocorrências como das respectivas áreas queimadas foram classificados de acordo com os meses do ano para se identificar a extensão da estação de incêndios no país.

\section{Causas dos incêndios}

Os incêndios que tiveram as prováveis causas identificadas foram classificados segundo os seguintes grupos: $a$ ) Raios; $b$ ) Queimas para limpeza; $c$ ) Incendiários; $d$ ) Fumantes; $e$ ) Fogos de recreação; $f$ ) Operações florestais; $g$ ) Estradas de ferro; $h$ ) Diversos. Os incêndios cujas causas não foram identificadas não fizeram parte das estatísticas, pois não é aconselhável incluir o grupo de causa "não determinada" a fim de forçar as pessoas a investigarem as causas.

\section{Tipo de vegetação atingida}

As informações retiradas dos questionários foram agrupadas de acordo com os seguintes tipos de vegetação: a) Eucalyptus spp; b) Pinus spp; c) Outras espécies plantadas; $d$ ) Floresta nativa; e) Outro tipo de vegetação, incluindo cerrado, capoeira e campo.

\section{Classes de tamanho}

Os incêndios foram também ordenados de acordo com as classes de tamanho (baseadas nas áreas queimadas) propostas por Ramsey \& Higgins (1981) e usadas internacionalmente: I) até 0,1 ha; II) de 0,1 a 4,0 ha; III) de 4,1 a 40,0 ha; IV) de 40,1 a 200,0 ha; V) mais de 200,0 ha. Esta informação é importante na avaliação da eficiência de combate no país.

\section{RESULTADOS E DISCUSSÃO}

Os resultados obtidos na pesquisa estão apresentados nos Quadros a seguir, que dão uma idéia do perfil dos incêndios ocorridos no país, em áreas protegidas, durante o período estudado. O número total de incêndios registrado neste trabalho não corresponde ao número total de incêndios ocorridos nas áreas protegidas, pois não foi possível obter respostas de todas as empresas florestais e unidades de conservação do país, seja por falta de registros ou por negativa de fornecimento dos dados. No entanto, as informações recebidas representam uma amostragem confiável dos incêndios ocorridos, possibilitando um correto diagnóstico do perfil dos incêndios no Brasil.

O quadro 1 mostra as ocorrências de incêndios e as áreas atingidas nas diversas regiões do país. Alguns estados, por não apresentarem número significativo de ocorrências em todo o período estudado, foram agrupados numa categoria denominada "Outros estados".

Dentre os estados que apresentaram dados mais consistentes e contínuos, durante o período pesquisado, Minas Gerais apresentou o maior número de incêndios e a maior área queimada. Isto se justifica pelo fato do estado apresentar a maior superfície reflorestada do país e por apresentar, em grande parte de seu território, uma estação seca prolongada, aumentando sensivelmente o risco de 
incêndios devido às condições favoráveis à propagação do fogo.

A extensa superfície atingida pelo fogo no grupo "Outros estados" foi produto de um grande incêndio em um estado do nordeste, mas deve ser considerado com um fato isolado pois a ocorrência de incêndios naquela região não é tão constante como em outros estados do sul, sudeste e centro-oeste.

O quadro 2 mostra a distribuição dos incêndios através dos meses do ano, possibilitando a definição da estação de incêndios no país, informação fundamental para um planejamento racional e econômico das atividades de prevenção e combate.

Quadro 1: Ocorrências de incêndios florestais e respectivas áreas queimadas, em áreas protegidas, nos estados brasileiros, no período de 1994 a 1997

Table 1: $\quad$ Fire occurrences and burned surfaces in brazilian states protected areas from 1994 to 1997

\begin{tabular}{|l|r|r|r|r||}
\hline \multirow{2}{*}{ ESTADO } & \multicolumn{2}{c|}{ INCÊNDIOS } & \multicolumn{2}{c||}{ ÁREA QUEIMADA } \\
\cline { 2 - 5 } & No. & $\%$ & Ha & 0,8 \\
\hline Bahia & 71 & 3,6 & $2.022,6$ & 25,2 \\
\hline Minas Gerais & 1.228 & 62,7 & $67.140,0$ & 0,3 \\
\hline Paraná & 187 & 9,6 & 671,7 & 1,8 \\
\hline Rio Grande do Sul & 77 & 3,9 & $4.800,1$ & 0,1 \\
\hline Santa Catarina & 53 & 2,7 & 173,1 & 1,7 \\
\hline São Paulo & 277 & 14,2 & $4.518,3$ & 29,8 \\
\hline Subtotal & 1.893 & 96,7 & $79.325,8$ & 70,2 \\
\hline Outros Estados & 64 & 3,3 & $186.620,2$ & 100,0 \\
\hline \hline TOTAL & 1.957 & 100,0 & $265.946,0$ & \\
\hline
\end{tabular}

Quadro 2: Distribuição das ocorrências de incêndios e respectivas áreas queimadas por mês, no período de 1994 a 1997

Table 2: $\quad$ Monthly distribution of fire occurrences and burned areas from 1994 to 1997

\begin{tabular}{||l|r|r|r|r||}
\hline \multirow{2}{*}{ MÊS } & \multicolumn{2}{|c|}{ INCÊNDIOS } & \multicolumn{2}{c|}{ ÁREA QUEIMADA } \\
\cline { 2 - 5 } & No. & $\%$ & ha & 0,4 \\
\hline \hline Janeiro & 56 & 2,9 & $1.033,4$ & 0,1 \\
\hline Fevereiro & 34 & 1,7 & 185,0 & 0,1 \\
\hline Março & 39 & 2,0 & 147,6 & 0,5 \\
\hline Abril & 41 & 2,1 & $1.234,2$ & 0,1 \\
\hline Maio & 69 & 3,5 & 154,7 & 42,1 \\
\hline Junho & 118 & 6,0 & 247,0 & 9,0 \\
\hline Julho & 298 & 15,2 & $113.394,8$ & 26,3 \\
\hline Agosto & 520 & 26,6 & $23.853,8$ & 4,8 \\
\hline Setembro & 463 & 23,7 & $70.008,8$ & 15,9 \\
\hline Outubro & 213 & 10,9 & $12.813,7$ & 0,2 \\
\hline Novembro & 54 & 2,8 & $42.358,0$ & 100,0 \\
\hline Dezembro & 52 & 2,7 & 515,0 & $265.946,0$ \\
\hline \hline TOTAL & 1.957 & 100,0 & & \\
\hline
\end{tabular}

Os dados do quadro 2 mostram que a estação de incêndios no país se estende de julho a novembro, quando foram registradas quase $80 \%$ das ocorrências e mais de $98 \%$ da área queimada. Estes resultados são idênticos aos observados no período 1983-1987 (Soares 1989), mostrando que, efetivamente, o problema dos incêndios florestais no Brasil se concentra no inverno e início da primavera, que corresponde à estação mais seca do ano em quase todo território nacional. Além disso, é nesta época que os agricultores fazem as queimas para preparo de terreno e limpeza de pastagens.

O quadro 3 mostra a distribuição dos incêndios por grupo de causa, informação importante para se direcionar as atividades de prevenção no sentido de se reduzir as causas mais freqüentes.

Os dados do quadro 3 indicam que a principal causa dos incêndios registrados no período estudado foram os "Incendiários", ou 
seja, pessoas que premeditadamente, por vingança, desequilíbrio mental, ou outro motivo, colocaram fogo na vegetação, ficando as "Queimas para limpeza" em segundo lugar. Este resultado mostra uma inversão de posições com relação ao observado no período 1983-1987 (Soares 1989), quando as "Queimas para limpeza" ocuparam o primeiro lugar, seguido dos "Incendiários".

Atualmente existe uma grande preocupação com o aumento de incêndios causados por incendiários em todo o mundo
(Soares 1997). Na Europa, de maneira geral, cerca de $50 \%$ dos incêndios têm sido causados por incendiários (ECE/FAO 1990). Incendiários ou fogos intencionais ocupam o primeiro lugar no número de incêndios registrados na África do Sul (REPUBLIC OF SOUTH AFRICA 1987), nos Estados Unidos (Brown \& Davis 1973), na Espanha (Velez 1990),na Grécia (Kailidis 1992) , na Itália (Leone \& Saracino 1990) e em Portugal (Almeida, Dias \& Gama 1990).

Quadro 3: Distribuição das ocorrências de incêndios e respectivas áreas queimadas, por grupo de causa, no período de 1994 a 1997

Table 3: $\quad$ Fire occurrences and burned areas distribution by cause group from 1994 to 1997

\begin{tabular}{||l|r|r|r|r||}
\hline \multirow{2}{*}{ CAUSA } & \multicolumn{2}{c|}{ INCÊNDIOS } & \multicolumn{2}{c||}{ ÁREA QUEIMADA } \\
\cline { 2 - 5 } & No. & $\%$ & ha & 3,7 \\
\hline \hline Diversos & 42 & 6,0 & $7.930,1$ & 0,0 \\
\hline Estradas de Ferro & 11 & 1,6 & 20,9 & 1,0 \\
\hline Fogos de Recreação & 23 & 3,3 & $2.244,3$ & 0,9 \\
\hline Fumantes & 43 & 6,1 & $1.987,6$ & 0,2 \\
\hline Incendiários & 396 & 56,6 & $42.623,9$ & 74,1 \\
\hline Operações Florestais & 21 & 3,0 & 467,7 & 0,3 \\
\hline Queimas para Limpeza & 155 & 22,1 & $159.633,3$ & 100,0 \\
\hline Raios & 9 & 1,3 & 592,4 & - \\
\hline Subtotal & 700 & 100,0 & $215.500,1$ & - \\
\hline Não determinada & 1.257 & - & $50.445,8$ & \\
\hline TOTAL & 1.957 & - & $265.946,0$ & \\
\hline
\end{tabular}

Quando se analisa a área queimada pelos incêndios as "Queimas para limpeza" $(74,1 \%)$ ocuparam a primeira posição, ficando os "Incendiários" $(19,8 \%)$ em segundo lugar. Isto se explica porque as queimadas para preparo de terreno e limpeza de pastos são feitas principalmente no inverno e início da primavera, justamente a época de maior risco de incêndios, devido à vegetação seca e às condições meteorológicas favoráveis à propagação do fogo. Assim, quando o fogo escapa do controle a tendência é uma rápida propagação, dificultando o combate e aumentando a área atingida. Já os incendiários provocam incêndios em qualquer época do ano e nem sempre as condições estão favoráveis a uma rápida propagação do fogo.

O quadro 4 mostra a distribuição das ocorrências de incêndios por tipo de vegetação, aqui classificada em cinco grupos.

Quadro 4: Distribuição das ocorrências de incêndios e respectivas áreas queimadas, por tipo de vegetação, no período de 1994 a 1997

Table 4: $\quad$ Fire occurreces and burned areas distribution by vegetation type from 1994 to 1997

\begin{tabular}{||l|r|r|r|r||}
\hline \multirow{2}{*}{ TIPO DE VEGETAÇÃO } & \multicolumn{2}{c|}{ INCÊNDIOS } & \multicolumn{2}{c||}{ ÁREA QUEIMADA } \\
\cline { 2 - 5 } & No. & $\%$ & ha \\
\hline Pinus spp. & 115 & 6,1 & $1.153,6$ & 0,4 \\
\hline Eucalyptus spp. & 591 & 31,6 & $14.729,7$ & 5,6 \\
\hline Outras florestas plantadas & 13 & 0,7 & 182,4 & 0,1 \\
\hline Florestas nativas & 410 & 21,9 & $243.124,8$ & 92,5 \\
\hline Outro tipo de vegetação & 744 & 39,7 & $3.519,2$ & 1,3 \\
\hline Subtotal & 1.873 & 100,0 & $262.709,7$ & 100,0 \\
\hline Não determinado & 84 & & $3.236,3$ & - \\
\hline Total & 1.957 & & $265.946,0$ & - \\
\hline
\end{tabular}

Como se observa no quadro 4, a maior incidência de incêndios, com quase $40 \%$ das ocorrências, foi no grupo "Outro tipo de vegetação", que engloba capoeira, cerrado e 
campo. Entre as espécies plantadas, a maior incidência foi em Eucalyptus spp, que é a espécie com maior área reflorestada no país, principalmente nas regiões central e norte de Minas Gerais, onde existe uma estação seca bastante longa durante o ano.

Com relação à área queimada, as "Florestas Nativas" foram as mais afetadas, permanecendo os eucaliptos em segundo lugar. Mesmo assim, mais de 14 mil hectares de eucalipto foram queimados durante o período analisado, o que representou um grande prejuízo para os reflorestadores.
No período 1983-1987 (Soares 1989) o maior número de incêndios foi observado nas plantações de eucalipto, ficando o grupo "Outro tipo de vegetação" em segundo lugar. Com relação à área atingida as posições se inverteram. Isto significa que nos dois períodos analisados as plantações de eucalipto tiveram a segunda maior área afetada pelos incêndios.

O quadro 5 mostra a distribuição dos incêndios através das classes de tamanho estabelecidas pelo Serviço Florestal do Canadá (Ramsey \& Higgins 1981) e usadas internacionalmente.

Quadro 5: Distribuição das ocorrências de incêndios e respectivas áreas queimadas, por classe de tamanho, no período de 1994 a 1997

Table 5: $\quad$ Fire occurrences an burned areas distribution by size class from 1994 to 1997

\begin{tabular}{||l|c|r|r|r||}
\hline \multirow{2}{*}{ CLASSE DE TAMANHO } & \multicolumn{2}{c|}{ INCÊNDIOS } & \multicolumn{2}{c|}{ ÁREA QUEIMADA } \\
\cline { 2 - 5 } & No. & $\%$ & ha \\
\hline \hline I (<0,1 ha) & 468 & 23,9 & 13,1 & 0,0 \\
\hline II ( 0,1-4 ha) & 961 & 49,1 & 983,3 & 0,4 \\
\hline III ( 4,1- 40 ha) & 334 & 17,1 & $4.999,6$ & 1,9 \\
\hline IV ( 40,1- 200 ha) & 147 & 7,5 & $8.755,8$ & 3,3 \\
\hline V ( > 200 ha) & 47 & 2,4 & $251.194,2$ & 94,5 \\
\hline \hline Total & 1957 & 100,0 & $265.946,0$ & 100,0 \\
\hline
\end{tabular}

A distribuição dos incêndios por classes de tamanho dá uma boa idéia da eficiência no controle dos incêndios. Quanto maior a porcentagem de incêndios na classe I mais eficiente o controle. Os dados do Quadro 5 mostram que quase $24 \%$ dos incêndios se enquadraram na Classe I, o que significa um avanço em relação aos dados do período 19831987 (Soares 1989), quando apenas 10,5\% das ocorrências ficaram nesta classe. Entretanto, quando comparado com outros países, este avanço ainda não foi suficiente para se afirmar que a eficiência de combate no Brasil é satisfatória. Na África do Sul, por exemplo, $39 \%$ dos incêndios ocorridos entre 1985 e 1989 se enquadraram na classe I (Kromhout 1990), enquanto no Canadá, onde a eficiência é maior ainda, 49\% dos incêndios ocorridos de 1969 a 1978 pertenciam à classe I (Ramsey \& Higgins 1981).

É importante ressaltar que os resultados aqui apresentados se referem à ocorrência de incêndios florestais e não de queimadas, conceitos às vezes confundidos não apenas pela imprensa mas também por pesquisadores de outras áreas. Por incêndio florestal se entende a propagação livre ou descontrolada do fogo em florestas e outras formas de vegetação. Queimada é a utilização do fogo, de maneira prescrita ou controlada, com um objetivo definido. Uma queimada pode, e muitas vezes ocorre, fugir do controle e se transformar em um incêndio, que neste caso será registrado como tal. Por isto, quando se lê na imprensa que, baseado em imagens de satélites, existem milhares de focos de incêndios no país, isto tecnicamente não é verdade, pois a grande maioria desses "pontos quentes" são queimadas e não incêndios. Aliás, nem todos os "pontos quentes" detectados pelos satélites são sequer queimadas, já que eles estão calibrados para temperaturas muito inferiores à temperatura de ignição da biomassa.

Finalmente deve-se reafirmar que o número de incêndios registrado neste trabalho não corresponde ao total das ocorrências observadas no país no período analisado. Em primeiro lugar, a pesquisa abrangeu apenas as áreas protegidas, isto é, propriedades de empresas florestais e unidades de conservação; não é possível coletar dados de incêndios que ocorrem em áreas rurais onde não há nenhum tipo de controle ou registro. Em segundo lugar, como se tratou de uma pesquisa baseada em 
informações fornecidas através de questionários, nunca se obtém total retorno dos mesmos; algumas empresas florestais e muitas unidades de conservação não mantém registro das ocorrências e outras simplesmente não forneceram os dados solicitados. No entanto, apesar dessas dificuldades, os resultados do trabalho representam uma boa amostragem das ocorrências verificadas no período estudado, possibilitando um perfeito diagnóstico do perfil dos incêndios florestais no território brasileiro.

\section{CONCLUSÕES}

Os resultados obtidos neste trabalho permitem concluir o seguinte:

- Dos estados que forneceram dados mais completos e consistente, Minas Gerais foi o que apresentou maior número de incêndios e maior área queimada.

- A estação de incêndios se estendeu de julho a novembro, onde se concentraram $79,2 \%$ das ocorrências e $98,6 \%$ da superfície queimada.

- "Incendiários" foi o principal grupo de causa dos incêndios, seguido de "Queimas para limpeza", invertendo-se a ordem com relação à extensão da área atingida.

- O maior número de ocorrências foi registrado em "Outro tipo de vegetação", seguindo-se as plantações de eucalipto e as florestas nativas; com relação à área atingida, as florestas nativas ocuparam o primeiro lugar, seguidas das plantações de eucalipto.

- O maior número de incêndios concentrou-se na classe de tamanho II, seguindo-se as classes I e III.

- A área queimada média, por incêndio, no período estudado foi de 135,89 ha.

\section{REFERÊNCIAS}

ALMEIDA, A.M.F.; DIAS, M.I.D. 1981. Estudo de vegetação em áreas queimadas em pinheiro bravo. Lisboa, Estação Florestal Nacional, INIA/MAP. 36p.

BROWN, A. A. \& DAVIS, K. P. 1973. Forest fire: control and use. New York, McGrawHill, $2^{\text {nd }}$ ed. 686p.
ECE/FAO 1990. Forest Fire Statistics 19851987. New Yor, United Nations, ECE/TIM $51.25 \mathrm{p}$.

KAILIDIS, D. S. 1992. Forest Fires in Greece. Athens, Proceedings of the Seminar on Forest Fire Prevention, Land Use and People: 27-40.

KROMHOUT, C. 1990. Analysis of Fire in Privately-Owned Plantations in Republic of South Africa :01/485 to31/03/89. South African Forestry Journal, $n^{\circ}$. 154: 74-87.

LEONE, V. \& SARACINO, A. 1990. Arson and Forest fire Industry: the state of the art in Italy. Coimbra, Proceeding of the International Conference on Forest Fire Research: A. 13-01/12.

RAMSEY, G. S. \& HIGGINS, D. G. 1981. Canadian Forest Fire Statistics. Ontario, Canadian Forestry Service, Information Report PI-X-9. 71p.

REPUBLIC OF SOUTH AFRICA 1987. Annual Report of the Department of Environment Affairs. Pretoria. 226p.

SOARES, R. V. 1984. Perfil dos Incêndios Florestais no Brasil em 1983. Brasil Florestal 58: 31-42.

SOARES, R. V. 1988. Perfil dos Incêndios Florestais no Brasil de 1984 a 1987. Floresta 18 (1/2): 94-121.

SOARES, R.V. 1989. Forest Fires in Brazilian Plantations and Other Protected Public Land. Freibug, Germany, Proceedings of the III Symposium on Fire Ecology, Vol. 1: 5-6.

SOARES, R. V. 1992. Ocorrência de Incêndios em Povoamentos Florestais. Floresta $22(1 / 2)$ 39-53.

SOARES, R. V. 1997. Arson: a Major Cause of Forest Fires. Vancouver, Canada, Proceedings of the 2nd International Wildland Fire Conference - Social Perspectives Section.

VELEZ, R. 1990. Field Research on Population Attitudes Concernig the Use of Fire in Forest Áreas. Coimbra, Proceedings of the International Conference on Forest Fire Research: A.01-1/7 


\section{APÊNDICE}

\section{Dados anuais de ocorrência de incêndios no período estudado}

Quadro 6: Distribuição das ocorrências de incêndios e áreas queimadas por estado, em 1994

Table 6: $\quad$ Fire occurrences and burned areas distribution by state in 1994

\begin{tabular}{|c|c|c|c|c|}
\hline \multirow{2}{*}{ ESTADO } & \multicolumn{2}{|c|}{ INCÊNDIO } & \multicolumn{2}{|c|}{ ÁREA QUEIMADA } \\
\hline & No. & $\%$ & ha & $\%$ \\
\hline Bahia & 28 & 4,6 & 114,9 & 0,1 \\
\hline Distrito Federal & 5 & 0,8 & $17.020,0$ & 11,2 \\
\hline Goiás & 8 & 1,3 & $4.481,9$ & 3,0 \\
\hline Minas Gerais & 434 & 71,0 & $41.166,2$ & 27,1 \\
\hline Paraná & 76 & 12,4 & 381,0 & 0,3 \\
\hline Piauí & 1 & 0,2 & $85.000,0$ & 56,0 \\
\hline Rio de Janeiro & 1 & 0,2 & 43,0 & 0,0 \\
\hline Rio Grande do Sul & 2 & 0,3 & 10,0 & 0,0 \\
\hline Santa Catarina & 14 & 2,3 & 39,5 & 0,0 \\
\hline São Paulo & 41 & 6,7 & $3.476,8$ & 2,3 \\
\hline Sergipe & 1 & 0,2 & 0,0 & 0,0 \\
\hline TOTAL & 611 & 100,0 & $151.733,2$ & 100,0 \\
\hline
\end{tabular}

Quadro 7: Distribuição das ocorrências de incêndios e respectivas áreas queimadas por mês em 1994 Table 7: $\quad$ Monthly distributions of fire occurrences and burned areas in 1994

\begin{tabular}{|c|c|c|c|c|}
\hline \multirow{2}{*}{ MÊS } & \multicolumn{2}{|c|}{ INCÊNDIO } & \multicolumn{2}{|c|}{ "ÁREA QUEIMADA } \\
\hline & No. & $\%$ & ha & $\%$ \\
\hline Janeiro & 10 & 1,6 & 4,5 & 0,0 \\
\hline Fevereiro & 15 & 2,5 & 9,3 & 0,0 \\
\hline Março & 9 & 1,5 & 98,4 & 0,1 \\
\hline Abril & 4 & 0,7 & $1.002,1$ & 0,7 \\
\hline Maio & 6 & 1,0 & 1,0 & 0,0 \\
\hline Junho & 30 & 4,9 & 45,6 & 0,0 \\
\hline Julho & 81 & 13,3 & $87.983,4$ & 58,0 \\
\hline Agosto & 134 & 21,9 & $16.604,0$ & 10,9 \\
\hline Setembro & 179 & 29,3 & $32.698,3$ & 21,6 \\
\hline Outubro & 123 & 20,1 & $11.180,3$ & 7,4 \\
\hline Novembro & 17 & 2,8 & $2.085,9$ & 1,4 \\
\hline Dezembro & 3 & 0,5 & 20,3 & 0,0 \\
\hline TOTAL & 611 & 10100,0 & $151.733,2$ & $\overline{1000,0}$ \\
\hline
\end{tabular}

Quadro 8: Distribuição dos incêndios e respectivas áreas queimadas, por grupo de causa, em 1994

Table 8: $\quad$ Fire occurences and burned areas distribution by cause group in 1994

\begin{tabular}{|c|c|c|c|c|}
\hline \multirow{2}{*}{ CAUSA } & \multicolumn{2}{|c|}{ INCÊNDIO } & \multicolumn{2}{|c|}{ ÁREA QUEIMADA } \\
\hline & No. & $\%$ & ha & $\%$ \\
\hline Diversos & 11 & 5,9 & $7.708,5$ & 5,6 \\
\hline Estrada de ferro & 2 & 1,1 & 3,0 & 0,0 \\
\hline Fogos de recreação & 10 & 5,4 & $1.967,6$ & 1,4 \\
\hline Fumantes & 19 & 10,2 & $1.559,6$ & 1,1 \\
\hline Incendiários & 77 & 41,4 & $16.271,4$ & 11,8 \\
\hline Operações florestais & 5 & 2,7 & 159,3 & 0,1 \\
\hline Queima para limpeza & 60 & 32,3 & $109.565,0$ & 79,5 \\
\hline Raios & 2 & 1,1 & 501,0 & 0,4 \\
\hline Sub- total & 186 & 100,0 & $137.735,3$ & 100,0 \\
\hline Não determinada & 425 & & $13.997,9$ & \\
\hline TOTAL & 611 & & $151.733,2$ & \\
\hline
\end{tabular}


Quadro 9: Distribuição das ocorrências de incêndios e respectivas áreas queimadas, por tipo de vegetação, em 1994

Table 9: $\quad$ Fire occurreces and burned areas distribution by vegetation type in 1994

\begin{tabular}{||l|r|r|r|r|}
\hline \multirow{2}{*}{ VEGETAÇÃO ATINGIDA } & \multicolumn{2}{c|}{ INCÊNDIO } & \multicolumn{2}{c|}{ ÁREA QUEIMADA } \\
\cline { 2 - 5 } & No. & $\%$ & ha & \multicolumn{1}{c|}{} \\
\hline \hline Pinus spp & 23 & 3,9 & 177,6 & 0,1 \\
\hline Eucalyptus spp & 148 & 25,5 & $6.150,4$ & 4,1 \\
\hline Outras florestas plantadas & 0 & 0,0 & 0,0 & 0,0 \\
\hline Floresta nativas & 132 & 22,7 & $144.813,9$ & 95,4 \\
\hline Cerrado & 4 & 0,7 & 166,3 & 0,1 \\
\hline Outro tipo de vegetação & 274 & 47,2 & 403,0 & 0,3 \\
\hline Sub-total & 581 & 100,0 & $151.711,2$ & 100,0 \\
\hline Não determinada & 30 & & 22,0 & \\
\hline TOTAL & 611 & & $151.733,2$ & \\
\hline
\end{tabular}

Quadro 10: Distribuição das ocorrências de incêndios e respectivas áreas queimadas, por classe de tamanho, em 1994

Table 10: Fire occurrences an burned areas distribution by size class in 1994

\begin{tabular}{|c|c|c|c|c|}
\hline \multirow{2}{*}{$\begin{array}{l}\text { CLASSE DE TAMANHO } \\
\text { (ha) }\end{array}$} & \multicolumn{2}{|c|}{ INCÊNDIO } & \multicolumn{2}{|c|}{ ÁREA QUEIMADA } \\
\hline & No. & $\%$ & ha & $\%$ \\
\hline $\mathrm{I}(<0,1)$ & 126 & 20,6 & 3,1 & 0,0 \\
\hline II $(0,1-4,0)$ & 321 & 52,5 & 310,7 & 0,2 \\
\hline III $(4,1-40,0)$ & 101 & 16,5 & 1560,8 & 1,0 \\
\hline IV $(40,1-200)$ & 37 & 6,1 & 3274,6 & 2,2 \\
\hline $\mathrm{V}(>200)$ & 26 & 4,3 & $146.584,0$ & 96,6 \\
\hline TOTAL & 611 & 100,0 & $151.733,2$ & 100,0 \\
\hline
\end{tabular}

Quadro 11: Distribuição das ocorrências de incêndios e respectivas áreas queimadas por estado, em 1995

Table 11: Fire occurrences and burned areas distribution by state in 1995

\begin{tabular}{|l|r|r|r|r||}
\hline \multirow{2}{*}{ ESTADO } & \multicolumn{2}{|c|}{ IINCÊNDIOS } & \multicolumn{2}{c|}{ ÁREA QUEIMADA } \\
\cline { 2 - 5 } & No. & $\%$ & \multicolumn{1}{c|}{ ha } & 0,9 \\
\hline \hline Bahia & 1 & 0,2 & 800,0 & 0,0 \\
\hline Distrito Federal & 1 & 0,2 & 0,0 & 0,1 \\
\hline Espírito Santo & 1 & 0,2 & 50,0 & 43,0 \\
\hline Goiás & 9 & 1,6 & $38.287,0$ & 0,2 \\
\hline Mato Grosso & 7 & 1,2 & 190,0 & 0,3 \\
\hline Mato Grosso do Sul & 11 & 2,0 & 306,3 & 4,8 \\
\hline Minas Gerais & 423 & 75,3 & $4.289,0$ & 0,0 \\
\hline Paraná & 6 & 1,1 & 9,1 & 45,0 \\
\hline Piauí & 1 & 0,2 & $40.000,0$ & 0,1 \\
\hline Rio de Janeiro & 3 & 0,5 & 72,0 & 5,2 \\
\hline Rio Grande do Sul & 29 & 5,2 & $4.590,9$ & 0,0 \\
\hline Santa Catarina & 11 & 2,0 & 36,5 & 0,4 \\
\hline São Paulo & 59 & 10,5 & 318,4 & 100,0 \\
\hline \hline TOTAL & 562 & 100,0 & $88.949,2$ & \\
\hline
\end{tabular}


Quadro 12: Distribuição das ocorrências de incêndios e respectivas áreas queimadas por mês em 1995

Table 12: Monthly distribution of fire occurrences and burned areas in 1995

\begin{tabular}{|c|c|c|c|c|}
\hline \multirow{2}{*}{ MESES } & \multicolumn{2}{|c|}{ INCENNDIOS } & \multicolumn{2}{|c|}{ "ÁREA QUEIMADA } \\
\hline & No. & $\%$ & ha & $\%$ \\
\hline Janeiro & 20 & 3,3 & 902,7 & $1,1,0$ \\
\hline Fevereiro & 2 & 0,4 & 0,1 & 0,0 \\
\hline Março & 7 & 1,2 & 18,4 & 0,0 \\
\hline Abril & 11 & 2,0 & 200,2 & 0,2 \\
\hline Maio & 14 & 2,5 & 6,8 & 0,0 \\
\hline Junho & 34 & 6,0 & 108,5 & 0,1 \\
\hline Julho & 94 & 16,7 & $5.719,6$ & 6,4 \\
\hline Agosto & 161 & 28,6 & $4.704,2$ & 5,3 \\
\hline Setembro & 154 & 27,4 & $35.963,2$ & 40,4 \\
\hline Outubro & 24 & 4,3 & 926,0 & 1,0 \\
\hline Novembro & 15 & 2,7 & $40.139,7$ & 45,1 \\
\hline Dezembro & 26 & 4,6 & 259,8 & 0,3 \\
\hline TOTAL & 562 & 100,0 & $88.949,2$ & 100,0 \\
\hline
\end{tabular}

Quadro 13: Distribuição das ocorrências de incêndios e respectivas áreas queimadas, por grupo de causa, em 1995 Table 13: Fire occurrences and burned areas distribution by cause group in 1995

\begin{tabular}{|c|c|c|c|c|}
\hline \multirow{2}{*}{ CAUSA } & \multicolumn{2}{|c|}{ INCÊNDIOS } & \multicolumn{2}{|c|}{ ÁREA QUEIMADA } \\
\hline & No. & $\%$ & ha & $\%$ \\
\hline Diversos & 14 & 8,1 & 79,2 & 0,1 \\
\hline Estradas de ferro & 0 & 0,0 & 0,0 & 0,0 \\
\hline Fogos de recreação & 5 & 2,9 & 77,6 & 0,1 \\
\hline Fumantes & 5 & 2,9 & 279,0 & 0,5 \\
\hline Incendiários & 106 & 61,3 & $14.270,6$ & 25,3 \\
\hline Operações florestais & 4 & 2,3 & 189,0 & 0,3 \\
\hline Queimas para limpeza & 38 & 22,0 & $41.531,4$ & 73,6 \\
\hline Raios & 1 & 0,6 & 5,0 & 0,0 \\
\hline Sub-total & 173 & 100,0 & $56.431,8$ & 100,0 \\
\hline Não determinada & 389 & & $32.517,5$ & \\
\hline TOTAL & 562 & & $88.949,2$ & \\
\hline
\end{tabular}

Quadro 14: Distribuição das ocorrências de incêndios e respectivas áreas queimadas, por tipo de vegetação, em 1995 Table 14: Fire occurreces and burned areas distribution by vegetation type in 1995

\begin{tabular}{|c|c|c|c|c|}
\hline \multirow{2}{*}{ VEGETAÇÃO ATINGIDA } & \multicolumn{2}{|c|}{ INCÊNDIOS } & \multicolumn{2}{|c|}{ ÁREA QUEIMADA } \\
\hline & No. & $\%$ & ha & $\%$ \\
\hline Pinus spp & 21 & 4,1 & 40,6 & 0,0 \\
\hline Eucalyptus spp & 159 & 31,3 & $3.720,0$ & 4,3 \\
\hline Outras Florestas Plantadas & 4 & 0,8 & 4,4 & 0,0 \\
\hline Florestas Nativas & 97 & 19,1 & $80.937,4$ & 94,4 \\
\hline Outro Tipo de Vegetação & 227 & 44,7 & $1.032,7$ & 1,2 \\
\hline Sub-total & 508 & 100,0 & $85.734,9$ & 100,0 \\
\hline Não determinado & 54 & & $3.214,3$ & \\
\hline TOTAL & 562 & & $88.949,2$ & \\
\hline
\end{tabular}


Quadro 15: Distribuição das ocorrências de incêndios e respectivas área queimadas, por classe de tamanho, em 1995

Table 15: Fire occurrences an burned areas distribution by size class in 1995

\begin{tabular}{||l|r|r|r|r|}
\hline \multirow{2}{*}{$\begin{array}{c}\text { CLASSE DE TAMANHO } \\
\text { (ha) }\end{array}$} & \multicolumn{2}{|c|}{ INCENDIOS } & \multicolumn{2}{c|}{ ÁREA QUEIMADA } \\
\cline { 2 - 5 } & No. & $\%$ & ha & 0 \\
\hline I $(<0,1)$ & 183 & 32,6 & 3,7652 & 0,0 \\
\hline II $(0,1-4,0)$ & 247 & 43,9 & 231,032 & 0,2 \\
\hline III $(4,1-40,0)$ & 90 & 16,0 & $1.399,61$ & 1,6 \\
\hline IV $(40,1-200)$ & 27 & 4,8 & $2.824,68$ & 3,2 \\
\hline V $(>200)$ & 15 & 2,7 & $84.490,15$ & 95,0 \\
\hline TOTAL & 562 & 100,0 & $88.949,24$ & 100,0 \\
\hline
\end{tabular}

Quadro 16: Distribuição das ocorrências de incêndios e respectivas áreas queimadas por estado, em 1996

Table 16: Fire occurrences and burned areas distribution by state in 1996

\begin{tabular}{|l|r|r|r|r|}
\hline \multirow{2}{*}{ ESTADO } & \multicolumn{2}{|c|}{ INCÊNDIOS } & \multicolumn{2}{c|}{ ÁREA QUEIMADA } \\
\cline { 2 - 5 } & No. & $\%$ & \multicolumn{1}{c|}{ ha } \\
\hline \hline Bahia & 32 & 8,0 & 348,6 & 1,6 \\
\hline Mato Grosso do Sul & 5 & 1,2 & 821,5 & 3,8 \\
\hline Minas Gerais & 188 & 46,9 & $19.773,0$ & 90,9 \\
\hline Paraná & 53 & 13,2 & 97,9 & 0,5 \\
\hline Piauí & 5 & 1,2 & 214,4 & 1,0 \\
\hline Rio de Janeiro & 1 & 0,2 & 4,0 & 0,0 \\
\hline Rio Grande do Sul & 15 & 3,7 & 65,4 & 0,3 \\
\hline Santa Catarina & 12 & 3,0 & 51,8 & 0,2 \\
\hline São Paulo & 90 & 22,4 & 378,6 & 1,7 \\
\hline TOTAL & 401 & 100,0 & $21.755,3$ & 100,0 \\
\hline
\end{tabular}

Quadro 17: Distribuição das ocorrências de incêndios e respectivas áreas queimadas por mês, em 1996

Table 17: Monthly distribution of fire occurrences and burned areas in 1996

\begin{tabular}{|c|c|c|c|c|}
\hline \multirow{2}{*}{ MÊS } & \multicolumn{2}{|c|}{ INCÊNDIOS } & \multicolumn{2}{|c|}{ ÁREA QUEIMADA } \\
\hline & No. & $\%$ & ha & $\%$ \\
\hline Janeiro & 7 & 1,7 & 72,4 & 0,3 \\
\hline Fevereiro & 9 & 2,2 & 12,3 & 0,1 \\
\hline Março & 4 & 1,0 & 0,6 & 0,0 \\
\hline Abril & 9 & 2,2 & 7,2 & 0,0 \\
\hline Maio & 27 & 6,7 & 122,3 & 0,6 \\
\hline Junho & 39 & 9,7 & 78,3 & 0,4 \\
\hline Julho & 78 & 19,5 & $19.177,8$ & 88,2 \\
\hline Agosto & 106 & 26,4 & $1.158,3$ & 5,3 \\
\hline Setembro & 54 & 13,5 & 396,9 & 1,8 \\
\hline Outubro & 43 & 10,7 & 563,3 & 2,6 \\
\hline Novembro & 14 & 3,5 & 110,6 & 0,5 \\
\hline Dezembro & 11 & 2,7 & 55,4 & 0,3 \\
\hline TOTAL & 401 & 100,0 & $21.755,3$ & 100,0 \\
\hline
\end{tabular}


Quadro 18: Distribuição das ocorrências de incêndios e respectivas áreas queimadas, por grupo de causa, em 1996 Table 18: Fire occurrences and burned areas distribution by cause group in 1996

\begin{tabular}{|c|c|c|c|c|}
\hline \multirow{2}{*}{ CAUSA } & \multicolumn{2}{|c|}{ INCÊNDIOS } & \multicolumn{2}{|c|}{ ÁREA QUEIMADA } \\
\hline & No. & $\%$ & ha & $\%$ \\
\hline Raios & 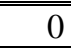 & 0,0 & 0,0 & 0,0 \\
\hline Queimas para limpeza & 31 & 16,9 & $7.714,4$ & 39,0 \\
\hline Fumantes & 11 & 6,0 & 43,1 & 0,2 \\
\hline Incendiários & 109 & 59,6 & $11.741,0$ & 59,4 \\
\hline Estradas de ferro & 4 & 2,2 & 5,1 & 0,0 \\
\hline Fogos de recreação & 3 & 1,6 & 49,0 & 0,2 \\
\hline Operações florestais & 8 & 4,4 & 84,2 & 0,4 \\
\hline Diversos & 17 & 9,3 & 142,4 & 0,7 \\
\hline Sub-total & 183 & 100,0 & $19.779,1$ & 100,0 \\
\hline Não determinada & 218 & & $1.976,2$ & \\
\hline TOTAL & 401 & & $21.755,3$ & \\
\hline
\end{tabular}

Quadro 19: Distribuição das ocorrências de incêndios e respectivas áreas queimadas, por tipo de vegetação, em 1996 Table 19: Fire occurreces and burned areas distribution by vegetation type in 1996

\begin{tabular}{||l|r|r|r|r||}
\hline \multirow{2}{*}{ VEGETAÇÃO ATINGIDA } & \multicolumn{2}{c|}{ INCÊNDIOS } & \multicolumn{2}{c||}{ ÁREA QUEIMADA } \\
\cline { 2 - 5 } & No. & $\%$ & \multicolumn{2}{c||}{ ha } \\
\hline Pinus spp & 21 & 5,2 & 40,6 & 0,2 \\
\hline Eucalyptus spp & 159 & 39,7 & $3.720,0$ & 17,1 \\
\hline Outras Florestas Plantadas & 4 & 1,0 & 4,4 & 0,0 \\
\hline Florestas Nativas & 97 & 24,2 & $16.957,7$ & 77,9 \\
\hline Outro Tipo de Vegetação & 120 & 29,9 & $1.032,7$ & 4,8 \\
\hline TOTAL & 401 & 100,0 & $21.755,3$ & 100,0 \\
\hline
\end{tabular}

Quadro 20: Distribuição das ocorrências de incêndios e respectivas áreas queimadas, por classe de tamanho, em 1996

Table 20: Fire occurrences an burned areas distribution by size class in 1996

\begin{tabular}{||l|r|r|r|r||}
\hline \multirow{2}{*}{$\begin{array}{c}\text { CLASSE DE TAMANHO } \\
(\mathrm{ha})\end{array}$} & \multicolumn{2}{|c|}{ INCÊNDIOS } & \multicolumn{2}{c||}{ ÁREA QUEIMADA } \\
\cline { 2 - 5 } & No. & $\%$ & \multicolumn{1}{c||}{ ha } & 0 \\
\hline \hline I (<0,1) & 110 & 27,4 & 3,1 & 0,0 \\
\hline II $(0,1-4,0)$ & 200 & 49,9 & 238,9 & 1,1 \\
\hline III $(4,1-40,0)$ & 67 & 16,7 & 886,6 & 4,1 \\
\hline IV $(40,1-200)$ & 20 & 5,0 & $1.506,8$ & 8,9 \\
\hline V (>200) & 4 & 1,0 & $19.120,0$ & 100,0 \\
\hline TOTAL & 401 & 100,0 & $21.755,3$ & 1,9 \\
\hline
\end{tabular}

Quadro 21: Distribuição das ocorrências de incêndios e respectivas áreas queimadas por estado, em 1997

Table 21: Fire occurrences and burned areas distribution by state in 1997

\begin{tabular}{||l|r|r|r|r||}
\hline \multirow{2}{*}{ ESTADO } & \multicolumn{2}{c|}{ INCÊNDIOS } & \multicolumn{2}{c||}{ ÁREA QUEIMADA } \\
\cline { 2 - 5 } & No. & $\%$ & \multicolumn{1}{c||}{ ha } & \multicolumn{1}{c||}{} \\
\hline Bahia & 10 & 2,6 & 759,0 & 21,6 \\
\hline Mato Grosso do Sul & 3 & 0,8 & 120,1 & 5,4 \\
\hline Minas Gerais & 183 & 47,8 & $1.911,8$ & 0,5 \\
\hline Pará & 1 & 0,3 & 10,0 & 5,2 \\
\hline Paraná & 52 & 13,6 & 183,7 & 3,8 \\
\hline Rio Grande do Sul & 31 & 8,1 & 133,8 & 1,3 \\
\hline Santa Catarina & 16 & 4,2 & 45,2 & 9,8 \\
\hline São Paulo & 87 & 22,7 & 344,5 & 100,0 \\
\hline \hline TOTAL & 383 & 100,0 & $3.508,2$ & \\
\hline
\end{tabular}


Quadro 22: Distribuição das ocorrências de incêndios e respectivas áreas queimadas por mês, em 1997

Table 22: Monthly distribution of fire occurrences and burned areas in 1997

\begin{tabular}{||l|r|r|r|r||}
\hline \multirow{2}{*}{ MÊS } & \multicolumn{2}{|c|}{ INCENDIOS } & \multicolumn{2}{c|}{ ÁREA QUEIMADA } \\
\cline { 2 - 5 } & No. & $\%$ & ha & \multicolumn{1}{c|}{} \\
\hline \hline Janeiro & 19 & 5,0 & 53,8 & 4,5 \\
\hline Fevereiro & 8 & 2,1 & 163,3 & 0,9 \\
\hline Março & 19 & 5,0 & 30,2 & 0,7 \\
\hline Abril & 17 & 4,4 & 24,7 & 0,7 \\
\hline Maio & 22 & 5,7 & 24,5 & 0,4 \\
\hline Junho & 15 & 3,9 & 14,7 & 14,6 \\
\hline Julho & 45 & 11,7 & 513,9 & 39,5 \\
\hline Agosto & 119 & 31,1 & $1.387,3$ & 27,1 \\
\hline Setembro & 76 & 19,8 & 950,4 & 4,1 \\
\hline Outubro & 23 & 6,0 & 144,1 & 0,6 \\
\hline Novembro & 8 & 2,1 & 21,8 & 5,1 \\
\hline Dezembro & 12 & 3,1 & 179,5 & 100,0 \\
\hline TOTAL & 383 & 100,0 & $3.508,2$ & \\
\hline
\end{tabular}

Quadro 23: Distribuição dos incêndios ocorridos e respectivas áreas queimadas, por grupo de causa, em 1997

Table 23: Fire occurrences and burned areas distribution by cause group in 1994 to 1997

\begin{tabular}{|c|c|c|c|c|}
\hline \multirow{2}{*}{ CAUSA } & \multicolumn{2}{|c|}{ INCÊNDIOS } & \multicolumn{2}{|c|}{ ÁREA QUEIMADA } \\
\hline & No. & $\%$ & ha & $\%$ \\
\hline Diversos & 0 & 0,0 & 0,0 & 0,0 \\
\hline Estradas de Ferro & 5 & 3,2 & 12,8 & 0,8 \\
\hline Fogos de Recreação & 5 & 3,2 & 150,1 & 9,7 \\
\hline Fumantes & 8 & 5,1 & 105,9 & 6,8 \\
\hline Incendiários & 104 & 65,8 & 340,9 & 21,9 \\
\hline Operações Florestais & 4 & 2,5 & 35,2 & 2,3 \\
\hline Queimada para Limpeza & 26 & 16,5 & 822,6 & 52,9 \\
\hline Raios & 6 & 3,8 & 86,4 & 5,6 \\
\hline Sub- total & 158 & 100,0 & $1.553,8$ & 100,0 \\
\hline Não determinada & 225 & & $1.954,3$ & \\
\hline TOTAL & 383 & & $3.508,2$ & \\
\hline
\end{tabular}

Quadro 24: Distribuição das ocorrências de incêndios e respectivas áreas queimadas, por tipo de vegetação, em 1997

Table 24: Fire occurreces and burned areas distribution by vegetation type in 1997

\begin{tabular}{||l|r|r|r|r||}
\hline \multirow{2}{*}{ VEGETAÇÃO ATINGIDA } & \multicolumn{2}{c|}{ INCÊNDIOS } & \multicolumn{2}{c|}{ ÁREA QUEIMADA } \\
\cline { 2 - 5 } & No. & $\%$ & \multicolumn{2}{c||}{ ha } \\
\hline Pinus spp & 50 & 13,1 & 894,9 & 25,5 \\
\hline Eucalyptus spp & 125 & 32,6 & $1.139,4$ & 32,5 \\
\hline Florestas nativas & 84 & 21,9 & 415,8 & 11,9 \\
\hline Outras florestas plantadas & 5 & 1,3 & 173,6 & 4,9 \\
\hline Outro tipo de vegetação & 119 & 31,1 & 884,5 & 25,2 \\
\hline TOTAL & 383 & 100,0 & $3.508,2$ & 100,0 \\
\hline
\end{tabular}


Perfil dos incêndios florestais no Brasil de 1994 a 1997

Quadro 25: Distribuição das ocorrências de incêndios e respectivas áreas queimadas, por classe de tamanho, em 1997

Table 25: Fire occurrences an burned areas distribution by size class in 1997

\begin{tabular}{||l|r|r|r|r||}
\hline \multirow{2}{*}{$\begin{array}{c}\text { CLASSE DE TAMANHO } \\
(\mathrm{ha})\end{array}$} & \multicolumn{2}{|c|}{ INCÊNDIOS } & \multicolumn{2}{c||}{ ÁREA QUEIMADA } \\
\cline { 2 - 5 } & No. & $\%$ & \multicolumn{1}{c||}{ ha } & 0,1 \\
\hline \hline $\mathrm{I}(<0,1)$ & 49 & 12,8 & 3,1 & 5,8 \\
\hline II $(0,1-4,0)$ & 193 & 50,4 & 202,7 & 32,9 \\
\hline III $(4,1-40,0)$ & 76 & 19,8 & $1.152,6$ & 32,8 \\
\hline IV $(40,1-200)$ & 63 & 16,4 & $1.149,7$ & 28,5 \\
\hline V $(>200)$ & 2 & 0,5 & $1.000,0$ & 100,0 \\
\hline TOTAL & 383 & 100,0 & $3.508,2$ & \\
\hline
\end{tabular}

